\title{
Liver transplantation for hepatocellular carcinoma: alpha- fetoprotein should be included in selection criteria
}

\author{
Hans-Christian Pommergaard
}

Department of Surgical Gastroenterology and Transplantation, Rigshospitalet, University of Copenhagen, Copenhagen, Denmark

Correspondence to: Hans-Christian Pommergaard, MD, PhD. Department of Surgical Gastroenterology and Transplantation, Rigshospitalet, University of Copenhagen, Blegdamsvej 9, 2100 Copenhagen, Denmark. Email: HCPommergaard@gmail.com.

Provenance: This is an invited Editorial commissioned by our Section Editor Dr. Guwei Ji (Liver Transplantation Center, The First Affiliated Hospital of Nanjing Medical University, Nanjing, China).

Comment on: Halazun KJ, Tabrizian P, Najjar M, et al. Is it Time to Abandon the Milan Criteria?: Results of a Bicoastal US Collaboration to Redefine Hepatocellular Carcinoma Liver Transplantation Selection Policies. Ann Surg 2018;268:690-9.

Received: 13 November 2018; Accepted: 28 November 2018; Published: 11 December 2018.

doi: $10.21037 / \operatorname{tgh} .2018 .12 .01$

View this article at: http://dx.doi.org/10.21037/tgh.2018.12.01

From the beginning it was clear that the prognosis was related to tumor characteristics in patients liver transplanted for hepatocellular carcinoma (HCC). Thus, selection criteria were needed to identify patients with survival comparable to that of non-malignant indications (1). In 1996, the Milan criteria (MC) were suggested based on size and number of HCC tumors (2). Unfortunately, MC exclude some patients with a good prognosis. These patients may present with a large tumor, however, without features of aggressive biological behavior represented by e.g., vascular invasion or high alpha-fetoprotein (AFP) levels (3-5). Despite this, MC are still recommended in recent European guidelines and as a result, most western centers still use MC (6-8).

Large efforts have been put into developing improved selection criteria and recent focus has been on including a surrogate marker for tumor biological behavior. A single measure of AFP was implemented in selection criteria in France in 2012 (9) after showing superiority to MC when used in conjunction with size and number of HCC tumors (French AFP model) (5). Lately, the founder of the MC developed a competing risk model using pretransplant AFP and imaging-based size and number of HCC tumors (10). The study showed that c-statistic for selecting patients was superior to previously proposed criteria including MC. In addition, the results were validated in a separate cohort from Shanghai.

Interestingly, locoregional treatment and response to such treatment while on waiting list have shown to be correlated with improved survival after transplantation
$(11,12)$. In addition, patients downstaged from being outside criteria have survival comparable to that of patients inside criteria $(13,14)$. This led to the suggestion that response to locoregional treatment may be an important tool to select patients (15).

In the recent study by Halazun et al. in Annals of Surgery (16), size and number of HCC tumors were combined with AFP response while on the waiting list. As the first US-based study evaluating AFP, the authors included 1,450 patients from three US centers between 2001 and 2013, of whom $82-88 \%$ received pretransplant locoregional treatment. AFP response was calculated as difference between maximum AFP at any time and the final immediate pretransplant AFP. In addition to the established prognostic feature of a single measure of AFP, the AFP response while on the waiting list may represent progression of disease as well as response to locoregional treatment. The authors established a score which performed well in a competing risk analysis and was superior to MC and the French AFP model regarding c-statistic. Overall, a reduction in AFP was more important than the absolute AFP level in predicting prognosis. Interestingly, patients with initial AFP $>1,000$, however, with a $>50 \%$ response had a good prognosis. These patients may be excluded by other criteria including only a single measure of AFP $(17,18)$. However, the results of the study were not validated in a separate cohort.

Despite high-quality evidence on AFP's utility, it was not possible to reach consensus to revise existing criteria in the European HCC guideline for 2018 (6). What it will take 
to reach agreement is unclear. Therefore, other countries may have to follow France's example and implement new criteria including AFP in some form despite lack of recommendation in guidelines.

\section{Acknowledgements}

None.

\section{Footnote}

Conflicts of Interest: The author has no conflicts of interest to declare.

\section{References}

1. Clavien PA, Lesurtel M, Bossuyt PM, et al. Recommendations for liver transplantation for hepatocellular carcinoma: an international consensus conference report. Lancet Oncol 2012;13:e11-22.

2. Mazzaferro V, Regalia E, Doci R, et al. Liver transplantation for the treatment of small hepatocellular carcinomas in patients with cirrhosis. N Engl J Med 1996;334:693-9.

3. Pommergaard HC, Rostved AA, Adam R, et al. Vascular invasion and survival after liver transplantation for hepatocellular carcinoma: a study from the European Liver Transplant Registry. HPB (Oxford) 2018;20:768-75.

4. D'Amico F, Schwartz M, Vitale A, et al. Predicting recurrence after liver transplantation in patients with hepatocellular carcinoma exceeding the up-to-seven criteria. Liver Transpl 2009;15:1278-87.

5. Duvoux C, Roudot-Thoraval F, Decaens T, et al. Liver transplantation for hepatocellular carcinoma: a model including alpha-fetoprotein improves the performance of Milan criteria. Gastroenterology 2012;143:986-94 e3; quiz e14-5.

6. European Association for the Study of the Liver. EASL Clinical Practice Guidelines: Management of hepatocellular carcinoma. J Hepatol 2018;69:182-236.

7. European Association for the Study of the Liver. EASL Clinical Practice Guidelines: Liver transplantation. J Hepatol 2016;64:433-85.

doi: $10.21037 / \operatorname{tgh} .2018 .12 .01$

Cite this article as: Pommergaard HC. Liver transplantation for hepatocellular carcinoma: alpha-fetoprotein should be included in selection criteria. Transl Gastroenterol Hepatol 2018;3:103.
8. De Carlis L, Di Sandro S, Centonze L, et al. Liverallocation policies for patients affected by HCC in Europe. Curr Transplant Rep 2016;3:313-8.

9. Costentin CE, Bababekov YJ, Zhu AX, et al. Is it time to reconsider the Milan Criteria for selecting patients with hepatocellular carcinoma for deceased-donor liver transplantation? Hepatology 2018. [Epub ahead of print].

10. Mazzaferro V, Sposito C, Zhou J, et al. Metroticket 2.0 Model for Analysis of Competing Risks of Death After Liver Transplantation for Hepatocellular Carcinoma. Gastroenterology 2018;154:128-39.

11. Otto G, Herber S, Heise M, et al. Response to transarterial chemoembolization as a biological selection criterion for liver transplantation in hepatocellular carcinoma. Liver Transpl 2006;12:1260-7.

12. Pommergaard HC, Rostved AA, Adam R, et al. Locoregional treatments before liver transplantation for hepatocellular carcinoma: a study from the European Liver Transplant Registry. Transpl Int 2018;31:531-9.

13. Yao FY, Mehta N, Flemming J, et al. Downstaging of hepatocellular cancer before liver transplant: long-term outcome compared to tumors within Milan criteria. Hepatology 2015;61:1968-77.

14. Ravaioli M, Grazi GL, Piscaglia F, et al. Liver transplantation for hepatocellular carcinoma: results of down-staging in patients initially outside the Milan selection criteria. Am J Transplant 2008;8:2547-57.

15. Mazzaferro V. Squaring the circle of selection and allocation in liver transplantation for HCC: An adaptive approach. Hepatology 2016;63:1707-17.

16. Halazun KJ, Tabrizian P, Najjar M, et al. Is it Time to Abandon the Milan Criteria?: Results of a Bicoastal US Collaboration to Redefine Hepatocellular Carcinoma Liver Transplantation Selection Policies. Ann Surg 2018;268:690-9.

17. Hameed B, Mehta N, Sapisochin G, et al. Alpha-fetoprotein level $>1000 \mathrm{ng} / \mathrm{mL}$ as an exclusion criterion for liver transplantation in patients with hepatocellular carcinoma meeting the Milan criteria. Liver Transpl 2014;20:945-51.

18. Available online: https://optn.transplant.hrsa. gov/media/1922/liver_hcc_criteria_for_auto_ approval_20160815.pdf. Accessed 29 October 2018. 